\title{
A Pilot Study Exploring Opinion and Belief of Parents towards Immunization Program of Oral Polio Vaccine (OPV) In Pediatric Ward in Gondar University Hospital, Northwest- Ethiopia
}

\author{
Akshaya Srikanth Bhagavathula ${ }^{1 *}$, Asim Ahmed Elnour ${ }^{2,3}$, AbdullaShehab ${ }^{4}$ \\ ${ }^{1}$ Department of Clinical Pharmacy, University of Gondar College of Medicine and Health Sciences, Gondar, Ethiopia. \\ ${ }^{2}$ Faculty-Pharmacy, Fatima College of Health Sciences, UAE. \\ ${ }^{3}$ Adjunct Associate Professor, Monash University,Australia. \\ ${ }^{4}$ Associate Professor, Internal Medicine Department; College of Medicine and Health Sciences-UAE University, UAE.
}

Received: August 29, 2016; Accepted: September 15, 2016; Published: October 3, 2016

*Corresponding author: Akshaya Srikanth Bhagavathula, Department of Clinical Pharmacy, Pharm D, College of Medicine and Health Sciences, School of Pharmacy, University of Gondar-Gondar, Ethiopia; Email: akshaypharmd@gmail.com

\begin{abstract}
Rational: Little attention has been given to evaluation of parents' knowledge and barriers towards poliomyelitis vaccination.
\end{abstract}

Aim: Explore knowledge and delineate barriers of parents to polio vaccine.

\section{Method}

Study design: This was a pilot study.

Study setting: Pediatric wards at University of Gondar referra teaching hospital, Northwest of Ethiopia.

Study population: was composed of parents of pediatric patients. A representative sample of 21 parents was use $\mathrm{d}$ in the pilot study.

Methodology: We have used an interview tool through in-depth interviews of parents attending pediatric wards.

Results: Study was carried out with twenty one parents (mean age $29.57 \pm 3.2$ years).More than half of parents were illiterate $(54.14 \%)$, dwelling in town (81.34\%) and with an average of 2.33 children. $80 \%$ of parents described their knowledge towards immunization with Oral Polio Vaccine was through community nursesand healthcare workers in hospitals. With the exception of2 parents, (95.2\%) knew the route of polio vaccination.

Conclusions: The main finding was the lack of structured education program tailored to parental of children at their age of receiving immunization with Oral Polio Vaccine.

Key words: Parental opinions and beliefs; Immunization by Polio vaccine; pilot study

\section{Background}

Poliomyelitis is a highly infectious disease leading to paralysis and deformity. Global immunization efforts and initiatives were made to eradicate poliomyelitis by the year 2000 [1]. A report published in October 2011stated that a total of 467 cases of wild poliomyelitis virus infection were from 11 countries and most of them were from sub-Saharan African countries like Democratic Republic of Congo, Angola, Central African Republic, Kenya and Nigeria and some of Asia's most populous countries like India, Pakistan and Afghanistan [2]. Ethiopia has the highest number of children suspected of polio due to suboptimal routine immunization coverage [3]. Despite the efforts undertaken by the government and international agencies, the proportion and necessities of immunization depend on existing gaps in the knowledge and awareness of the people regarding immunization. In studies from Ethiopia, low access to services and inadequate awareness of the roles of immunization were found to be barriers to completion of child vaccination series [4-6].

\section{Rational}

Earlier studies have explored immunization by focusing on the socio-demographic and socio-economic factors of child health, but little attention has been given to evaluation of the parents' knowledge and barriers towards poliomyelitis vaccination of their children in Ethiopia. Parental assessment regarding immunization with Oral Polio Vaccine (OPV) is very important to improve immunization rate.

\section{Aim}

The purpose of this study was to explore the knowledge and delineate barriers of parents who have been attendees of their children attending pediatric ward in University of Gondar referral teaching hospital located in Northwest of Ethiopia, towards immunization with OPV.

\section{Method}

The study was approved by the university ethics committee. 
Study design: This was a pilot study.

Study setting: Study was conducted in pediatric ward at University of Gondar referral teaching hospital, in Gondar cityNorthwest Ethiopia. The Gondar university hospital (Bed capacity 350 beds) and the pediatric ward contain 21 beds capacity with 2 consultants, 4 Resident and 10 medical interns.

Study population: The population was composed of parents of pediatric patients. A representative sample of 21 parents was used in the pilot study. The sample was selected by non random consecutive sampling technique. Parents were invited and agreed participants were consented post reading of study information sheet.

\section{Methodology}

The demographics of parents and their children were collected via the administration of questionnaire administered by the clinical pharmacist. Information for occupation, education, marital status (married/divorced/widow), residency (town/ rural/remote area), number of children's and age of last child was also collected by the question naire. We have used an interview tool through in-depth interviews of parents attending pediatric wards. The tool was a concise questionnaire asking parents their knowledge about polio: Are you familiar of a disease called "POLIO", what is the source of parents information ,are you aware where to get vaccinated for polio vaccines, are you aware that polio vaccines are provided free of cost, have you ever vaccinate your child for polio, if yes then how recent, from where you vaccinated and who told you to vaccinate, does any vaccination people ever came to your home to vaccinate, how the polio vaccine is given like tablets, injections, drops.

We have also addressed barriers of polio vaccination by two questions: if you have not vaccinated your child recently "what was the reason" and what is the specific reason that may hinder you to vaccinate your child against polio.

\section{Results}

Our study was carried out with twenty one parents (mean age $29.57 \pm 3.2$ years). The mean children age was $3.62 \pm 3.47$ and the mean number of children was $2.33 \pm 1.52$. The parents mean age was $30 \pm 8.1$ for females and $29 \pm 4.8$ for males.

More than half of parents were illiterate (54.14\%), dwelling in town $(81.34 \%)$ and with an average of 2.33 children. Less than one third $(28.6 \%)$ of parents has an idea and knowledge about polio and were familiar with the disease called "POLIO". After in-depth interview with interviewees, about $80 \%$ of parents described their knowledge towards immunization with polio vaccine was through community nurses and healthcare workers in hospitals. $33.3 \%$ were aware where to get vaccinated with "POLIO vaccine", while (38.1\%) were aware that polio vaccines were provided free of cost, Furthermore $52.3 \%$ have vaccinated their child for POLIO and few parents $15.3 \%$ have declared that POLIO vaccination person came to their home. Very few parents $(9.5 \%)$ know the source of information about POLIO and less than quarter $(19.0 \%)$ knew the sources of information about POLIO. However, the same percent of parents $19 \%$ indicated that
POLIO vaccine was given to their children. With the exception of 2 parents, (95.2\%) knew the route of polio vaccination.

\section{Parental barriers to POLIO immunization}

The main barriers to OPV have been addressed by the parents were lack of awareness from healthcare workers, not aware of importance of OPV, lack of structured informative parental program and access to services.

\section{Discussions}

The main finding of this pilot study was the lack of structured education program tailored to parental of children at their age of receiving immunization with OPV. We have reported that an appreciated percent of interviewed parents admitted the fact that no specific education and no awareness was provided towards immunization with polio vaccineand no awareness was informed about polio immunization. This finding was concordant with earlier reports $[5,6,8]$.In our study, it was observed that polio campaigns in Ethiopia lack conducting face-to-face communication between parents and healthcare immunization workers for better understanding of the importance of polio vaccination, increasing the knowledge and minimizing the barriers regarding polio immunization among parents.

Our findings towards knowledge were similar to Bonuand and coworkers [7]; where they highlighted the diversities of polio eradication initiatives between sub-Saharan Africa and South Asia. In Rwanda and Rubavu [8], researchers trained the polio campaigning staff prior to each campaign and provided other services to public to lay out clear plans to transfer additional knowledge and polio-related information to the public. In some cases contributing workers' fatigue through repetition can weaken the focus in providing polio-related information to the public. The social workers and community leaders play a significant role in imparting knowledge to the child bearing families by reaching out to the masses and motivating them.

\section{Parental barriers to immunization by polio vaccine}

Some studies highlighted that in Ethiopia, the polio eradication program has delivered its most unambiguously positive impacts and all efforts continue to focus on providing polio vaccination to children across the country, but the barriers and misconceptions remain questionable.

\section{Parental beliefs}

We have observed that there was non-belief about effectiveness of OPV and some of the parents mentioned difficulty in communicating, and fear of side effects. Similar results were reported in one study [9].

\section{Economic barriers}

Evidences suggest that the high-income families are adequately immunized and those most children in this group receive oral and injectable polio vaccines through pediatricians in the private sector [10].

Several factors make the goal of eradicating polio in Ethiopian 
elusive; many factors may lead to clustering of unimmunized children, who are at high risk of getting polio. It was evident from the Ethiopian Demographic and Health survey-EDHS reports in 2011 , that only $24 \%$ of the children aged $12-23$ months were fully vaccinated [11].

Recently, there is a global growing concerns and fear about POLIO disease and unvaccinated children in areas such as Afghanistan and Syria. Furthermore the cross boarder of refugees and those fleeing from war called for WHO to recall their global concerns about POLIO outbreaks. In this respect, more strategic WHO POLIO program should incorporate these conflicts and collaborate with United Nations and concerned authorities to limit the spread of POLIO in such areas.

Despite global achievements, vaccine refusal and scant information on the importance and availability of OPV at the community level continue to impede poliomyelitis eradication efforts in some African countries. One of the strategic solutions is to engage the community to raise the acceptance of OPV [12-14]. This can be achieved by active involvement of traditional leaders in the communities and villages to encourage the parents for OPV. The idea is to enhance the bottom of societies in rural areas and scanty communities where no health services or health setup facilities are available.

\section{Conclusions}

Lack of knowledge and misperceptions about polio vaccination lead to continued polio transmission in the Ethiopian population unless targeted activities are undertaken to promote immunization.

There is a need to raise the parental educational awareness and knowledge about the benefits and importance of immunization by

Table 1: The demographics of parents.

\begin{tabular}{|l|l|l|}
\hline & $\begin{array}{l}\text { Male } \\
\text { F, (\%) - 9, (42.8) }\end{array}$ & $\begin{array}{l}\text { Female } \\
\text { F, (\%) - 12, (57.2) }\end{array}$ \\
\hline Mean Age (Years) & $29 \pm 4.8$ & $30 \pm 8.1$ \\
\hline Occupation & \multicolumn{2}{|l|}{} \\
\hline No work or Housewife & - & $4(33.4)$ \\
\hline Merchant & $4(44.4)$ & $1(8.3)$ \\
\hline Driver & $1(11.2)$ & $1(8.3)$ \\
\hline Farmer & $4(44.4)$ & $2(16.6)$ \\
\hline $\begin{array}{l}\text { Others (Teacher, office } \\
\text { etc) }\end{array}$ & - & $4(33.4)$ \\
\hline Education & & $7(58.3)$ \\
\hline Illiterate & $5(55.6)$ & $2(16.7)$ \\
\hline Primary school & $3(33.3)$ & $3(25.0)$ \\
\hline University graduate & $1(11.1)$ & $12(100.0)$ \\
\hline Residency & & - \\
\hline Town dwellers & $6(66.7)$ & $12(57.2)$ \\
\hline Village dwellers & $3(33.3)$ & \\
\hline Total F=21, (100.0) & $9(42.8)$ & \\
\hline Key: F= frequency, (\%) & percentage. & \\
\hline
\end{tabular}

Table 2: Parental questionnaire (21 parents)

\begin{tabular}{|c|c|c|}
\hline Question & $\begin{array}{l}\text { Yes } \\
\text { F (\%) }\end{array}$ & $\begin{array}{l}\text { No } \\
\text { F (\%) }\end{array}$ \\
\hline \multicolumn{3}{|l|}{ Part A Knowledge about polio: } \\
\hline $\begin{array}{l}\text { 1. Are you familiar with the disease called } \\
\text { "POLIO"? }\end{array}$ & $6(28.6)$ & $15(71.4)$ \\
\hline $\begin{array}{l}\text { 2. Are you aware where to get vaccinated with } \\
\text { "POLIO vaccine" }\end{array}$ & 7 (33.3) & $14(66.7)$ \\
\hline $\begin{array}{l}\text { 3. Are you aware that POLIO vaccine is } \\
\text { provided free of cost? }\end{array}$ & $8(38.1)$ & $13(61.9)$ \\
\hline $\begin{array}{l}\text { 4. Have you ever vaccinated your child against } \\
\text { POLIO? }\end{array}$ & $11(52.3)$ & $10(47.7)$ \\
\hline $\begin{array}{l}\text { 5. Does any POLIO vaccination person ever } \\
\text { came to your home? }\end{array}$ & $3(14.3)$ & $18(85.7)$ \\
\hline $\begin{array}{l}\text { 6. What is the source of your information } \\
\text { about "POLIO" (Known) }\end{array}$ & $2(9.5)$ & $19(90.5)$ \\
\hline $\begin{array}{l}\text { 7. Who have told you to vaccinate your child } \\
\text { against POILO? (Known) }\end{array}$ & $4(19.0)$ & $17(79.0)$ \\
\hline $\begin{array}{l}\text { 8. How POLIO vaccine is given to your child, in } \\
\text { what form? (Known) }\end{array}$ & $4(19.0)$ & $17(79.0)$ \\
\hline
\end{tabular}

what form? (Known)

Part B Barriers to POLIO vaccination:

1. What was the reason for not vaccinating your child against POLIO? (Parent gave the reason)

2. Is there any specific reason that may hinder you to vaccinate your child against POLIO? (Parent gave the reason)

$5(23.8) \quad 16(76.2)$

Key: $\mathbf{F}=$ frequency, $(\%)=$ percentage.

Note:

Part A: Questions 6 to 8 were reported as know the answer (Yes) or does not know the answer (No).

Part B: Questions 1 and 2 were reported as parent gave the answer (Yes) or did not give the answer (No).

polio vaccination. The concern of the deleterious consequences that results from non-complete immunization deserves special attention.

We recommend that the relevant government authorities take proactive measures to improve the access to the polio vaccination program. The benefits of polio vaccination need to be well understood by the parents to immunize their children.

- Highlights:Evaluation of the parents' knowledge about POLIO is imperative in low socio-economic population.

- Studying the barriers towards poliomyelitis vaccination deserve attention.

Parental assessment regarding immunization with Oral Polio Vaccine (OPV) is very important to improve immunization rate.

\section{References}

1. De Vries AS, Harper J, Murray A, Lexau C, Bahta L, Christensen J, et al. Vaccine-derived poliomyelitis 12 years after infection in Minnesota. $\mathrm{N}$ Engl J Med. 2011;364(24): 2316-2323.

2. Gonzalez H, Olsson T, Borg K. Management of postpolio syndrome. LancetNeurol. 2010;9(6): 634-642. doi: 10.1016/S14744422(10)70095-8. 


\section{Northwest-Ethiopia}

3. Mesfin G, Schluter W, Gebremariam A, Benti D, Bedada T, Beyene B et al. Polio outbreak response in Ethiopia. East Afr Med J. 2008;85(5) 222-231.

4. Berhane Y. Universal Childhood Immunization: a realistic yet not achieved goal. Ethiop J Health Dev. 2008;22(2):146-147.

5. Okwaraji YB, Mulholland Kim, Schellenberg JA, Andarge G, Admassu M, Edmond KM. The association between travel time to health facilities and childhood vaccine coverage in rural Ethiopia - A community based cross sectional study. BMC Public Health. 2012;12:476. Doi 10.1186/1471-2458-12-476.

6. Etana B, Deressa W. Factors associated with complete immunization coverage in children aged 12-23 months in Ambo Woreda, Central Ethiopia. BMC Public Health. 2012;12:566

7. Bonu S, Rani M, Razum O. Global Public Health Mandates in a Diverse World: The Polio Eradication Initiative and the Expanded Programme on Immunization in Sub-Saharan Africa and South Asia. Health Policy. 2004;70(3):327-345.

8. Closser S, Cox K, Parris TM, Landis M, Justin J, Ranjani Gopinath et al The impact of polio eradication on routine immunization and primary health care: a mixed-methods study. J Infect Dis. 2014. doi:10.1093/ infdis/jit232.
9. Khowain AR, Khan SA, Nizam N, Omer SB, Zaid A. Parental perception surrounding polio and self-reported non-participation in polio supplementary immunization activities in Karachi, Pakistan: a mixed methods study. Bull World Health Organ. 2012;90:822-830.

10. Smith PJ, Jain N, Stevenson J, Männikkö N, Molinari NA. Progress in timely vaccination coverage among children living in low-income households. Arch PediatrAdolesc Med. 2009;163(5): 462-468. doi: 10.1001/archpediatrics.2009.25

11. Ethiopia Federal Ministry of Health. The national routine immunization update, June 2005.

12.Ghinail, WillottC, DadariI, LarsonHJ. Listening to the rumours: what the northern Nigeria polio vaccine boycott can tell us ten years on. Glob Public Health. 2013;8(10):1138-1150. Doi: 10.1080/17441692.2013.859720.

13. AbimbolaS, MalikAU, MansoorGF. The final push for polio eradication addressing the challenge of violence in Afghanistan, Pakistan, and Nigeria. PLoS Med. 2013

14. MangalTD, AylwardRB, MwanzaM, Gasasira A, Abanida E, Pate MA et al. Key issues in the persistence of poliomyelitis in Nigeria: a case control study. Lancet Glob Health. 2014;2(2) e90-e7. Doi: 10.1016/ S2214-109X(13)70168-2. 